\title{
PENGENALAN EKONOMI ISLAM DAN AKAD-AKAD BANK SYARIAH DI SMK KAB. KUANTAN SINGINGI
}

\author{
Mohd. Winario', M. Khoir Al-Kusyairi1 ${ }^{1}$ \\ 1) Sekolah Tinggi Ekonomi Islam (STEI) Iqra Annisa Pekanbaru \\ Email: mohd.winario@gmail.com
}

\begin{abstract}
ABSTRAK
Pengabdian ini dilakukan di SMK Se-Derajat Kabupaten Kuantan Singingi. Pengabdian ini bertujuan untuk mensosialisasikan ekonomi islam dan akad-akad pada bank syariah di SMK Kabupaten Kuantan Singingi, yang menjadi objeknya adalah SMKN 2 Teluk Kuantan dan SMKN 1 Kuantan Mudik. Hasil dari pengabdian ini menunjukkan bahwa: 1) Keberhasilan target jumlah peserta pelatihan. 2) Ketercapaian tujuan kegiatan. 3) Ketercapaian target materi yang telah direncanakan. 4) Kemampuan peserta dalam penguasaan materi. Secara keseluruhan kegiatan pengabdian ini dapat dikatakan berhasil. Keberhasilan ini selain diukur dari keempat komponen di atas, juga dapat dilihat dari kepuasan peserta setelah mengikuti kegiatan karena tim pengabdi memberikan kesempatan bertanya sebanyak-banyaknya dan ketika tim pengabdi memberikan pertanyaan dapat dijawab oleh siswa, apalagi bagi siswa yang bisa menjawab diberikan hadiah. Manfaat yang diperoleh peserta adalah pengetahuan dan pemahaman tentang ekonomi islam dan akad-akad bank syariah.
\end{abstract}

Kata kunci: Pengenalan, Ekonomi Islam, Akad, Bank Syariah

\begin{abstract}
This devotion is done in SMK Se-Degrees Kuantan Singingi Regency. This devotion aims to socialize Islamic economics and akad-akad on syariah banks in SMK Kuantan Singingi District, which became the object is SMKN 2 Teluk Kuantan and SMKN 1 Kuantan Mudik. The results of this dedication show that: 1) The success of the target number of trainees. 2) Achievement of activity objectives. 3) Achievement of material targets that have been planned. 4) The ability of participants in the mastery of the material. Overall, this activity is successful. This success in addition to measured from the four components above, can also be seen from the satisfaction of participants after attending the activity because the team of devotees gave the opportunity to ask as much as possible and when the team of devotees to give questions can be answered by the students, especially for students who can answer given the prize. Benefits obtained by participants are knowledge and understanding of Islamic economics and syariah bank contracts.
\end{abstract}

Key words: Introduction, Islamic Economics, Contract, Islamic Bank 


\section{PENDAHULUAN}

SMK atau Sekolah Menengah Kejuruan, adalah sekolah setingkat SMU yang lebih menekankan kepada penguasaan kompetensi praktis dalam rangka mempersiapkan lulusan yang siap pakai dan siap kerja. Belakangan ini pertumbuhan SMK meningkat pesat di Indonesia.

Ada beberapa hal yang membuat SMK akhir-akhir ini menjadi pusat perhatian dalam dunia pendidikan menengah:

1. SMK dipandang mampu menjawab tantangan kerja. Lulusan SMK dipandang lebih terampil dan lebih siap untuk memasuki dunia kerja (cari uang) dibandingkan dengan SMU. Dengan demikian SMK dipandang mampu mengurangi tingkat pengangguran di Republik tercinta ini, sehingga pantas pemerintah akhir-akhir ini 'menganakemaskan' SMK.

2. Bantuan dana berupa subsidi pemerintah untuk penyelenggaraan pendidikan di SMK menjadi prioritas. Inilah sisi lain dari daya tarik SMK bagi para penyelenggara pendidikan.

3. Daya dukung dan respon masyarakat cukup signifikan terhadap keberadaan SMK. SMK dipandang mampu menyatukan dua kepentingan masyarakat, yaitu kepentingan pragmatis dan idealismenya. Dari sisi pragmatis, masyarakat lebih mendukung jika anak-anak mereka setelah lulus sekolah mampu bekerja ketimbang menjadi pengangguran. Dari sisi idealisme, lulusan SMK juga dapat meneruskan pendidikannya ke jenjang yang lebih tinggi di perguruan tinggi manapun, baik negeri maupun swasta.

Saat ini lebih dari 40 program/jurusan yang ada pada SMK. Dari semua jurusan tersebut dapat diklasifikasikan secara umum kepada jurusan teknik dan non teknik. Jika dibandingkan dengan SMU dan MA yang hanya terdiri dari jurusan Ilmu Alam, Ilmu Sosial, Ilmu Bahasa dan Agama, SMK lebih memberikan alternatif pemilihan jurusan yang lebih banyak. Dari sekian banyak jurusan yang terdapat di SMK, hampir semuanya mencakup pada bidang-bidang yang menyerap tenaga kerja. Misalnya, perbengkelan diarahkan agar lulusannya mampu bekerja di bengkel dan jurusan lainnya, seolah-olah ingin menutup peluang kerja bagi lulusan-lulusan non SMK.

Kabupaten Kuantan Singingi yang merupakan pemekaran dari kabupaten Indragiri Hulu. Kabupaten Kuantan Singingi (Kuansing) adalah salah satu kabupaten di Provinsi Riau, Indonesiandonesia. Kabupaten Kuansing disebut pula dengan rantau kuantan atau sebagai daerah perantauan orang-orang Minangkabau (Rantau nan Tigo Jurai), Dalam kehidupan sehari-hari, masyarakat Kuansing menggunakan adat istiadat serta bahasa minangkabau. Kabupaten ini berada di bagian barat daya Provinsi Riau dan merupakan pemekaran dari Kabupaten Indragiri Hulu. (wikipedia.org/wiki).

Kabupaten Kuantan singingi mempunya 10 SMK, 7 SMK Negeri dan 3 SMK Swasta, seperti terlihat dalam tabel 1 berikut: 
Tabel 1 Daftar SMK di Kabupaten Kuantan Singingi

\begin{tabular}{cllc}
\hline No & Nama Sekolah & Alamat & Status \\
\hline 1 & SMK Kecil Logas Tanah Darat & Perhentian Luas & Swasta \\
\hline 2 & SMK Terpadu TBS & T B S & Swasta \\
\hline 3 & SMKN Kuantan Mudik & Pasar Lubuk Jambi & Negeri \\
\hline 4 & SMKN 1 Benai & Jl. Juhum Ismail 2 & Negeri \\
\hline 5 & SMKN 1 Logas Tanah Darat & Logas Tanah Darat & Negeri \\
\hline 6 & SMKN 1 Singingi Hilir & Singingi Hilir & Negeri \\
\hline 7 & SMKN 1 Teluk Kuantan & Teluk Kuantan & Negeri \\
\hline 8 & SMKN 2 Teluk Kuantan & Teluk Kuantan & Negeri \\
\hline 9 & SMKN 3 Teluk Kuantan & Sinambek & Negeri \\
\hline 10 & SMKS Muhammadiyah Cerenti & Cerenti & Swasta \\
\hline
\end{tabular}

Beberapa SMK yang tim pengabdi ambil sebagai tempat kegiatan adalah SMKN 2 Teluk Kuantan dan SMKN 1 Kuantan Mudik.

\section{Batasan Masalah}

Dalam pengabdian masyarakat ini memfokuskan pada pengenalan ekonomi islam dan akad-akad bank syariah.

\section{Perumusan Masalah}

Bagaimanakah pemahaman siswa SMK tentang ekonomi islam dan akad-akad bank syariah.

\section{Tujuan Kegiatan Pengabdian}

Tujuan dari kegiatan pengabdian masyarakat ini adalah: Untuk mengetahui pemahaman siswa SMK tentang ekonomi islam dan akad-akad bank syariah.

\section{Manfaat Kegiatan}

Manfaat kegiatan pengabdian masyarakat ini adalah sebagai berikut:

a. Siswa SMK di Teluk Kuantan, Kab. Kuantan Singingi mengetahui pentingnya mengetahui ekonomi islam dan akad-akad bank syariah.

b. Mengaplikasikan ilmu ke masyarakat terutama di siswa SMK di Teluk Kuantan, Kab. Kuantan Singingi.

\section{Masyarakat Sasaran}

Agar pengabdian masyarakat ini mengenai sasaran yang jelas, tim pengabdi bekerjasama dengan pihak sekolah (SMK di Teluk Kuantan, Kab. Kuantan Singingi) terutama Kepala Sekolahnya dan guru-guru sekolah untuk memfasilitasi kegiatan pengabdian masyarakat ini.

\section{TINJAUAN PUSTAKA}

Menurut UU No. 21 Tahun 2008 tentang perbankan syariah, bank syariah adalah bank yang menjalankan kegiatan usahanya berdasarkan prinsip syariah dan menurut jenisnya terdiri atas Bank Umum Syariah, Unit Usaha Syariah, dan Bank Pembiayaan Syariah (Ismail, 2011). 
Bank syariah memiliki beberapa karakteristik tertentu yang membedakan dengan bank konvesional antara lain (Soemitra, 2009: 67)

1. Penghapusan riba. Penghapusan riba ini sesuai dengan Al-Qur'an dan Hadist yang mengharamkan riba tersebut.

2. Pelayanan kepentingan publik dan merealisasikan sasaran sosio-ekonomi Islam. Dalam bank syariah, bisnis dan usaha yang dilaksanakan tidak terlepas dari saringan syariah. Oleh karena itu, bank syariah tidak akan mungkin membiayai usaha yang terkandung didalamnya hal-hal yang diharamkan.

3. Bank syariah bersifat universal yang merupakan gabungan dari bank komersil dan bank investasi. Adanya pola pikir sebagian masyarakat Indonesia yang lebih nyaman menabung di bank syariah membuat bank komersial dan bank investasi membuka unit syariahnya untuk menarik nasabah tersebut.

4. Bank syariah akan melakukan evaluasi yang lebih berhati- hati terhadap permohonan pembiayaan yang berorientasi kepada penyertaan modal, karena bank komersil syariah menerapkan profit and loss sharing dalam konsinyasi, ventura, bisnis atau industri.

5. Bagi hasil cenderung mempererat hubungan antara bank syariah dan pengusaha karena sistem bagi hasil ini adil dengan perhitungannya berdasarkan hasil usaha.

6. Kerangka yang dibangun dalam membantu bank mengatasi kesulitan likuiditasnya dengan memanfaatkan instrumen bank pasar uang antar bank syariah dan instrumen bank syariah berbasis syariah.

Menurut Muhammad Abdallah dan Irsyad Lubis, Faktor reputasi bank mempengaruhi minat siswa MAN dalam memutuskan menabung pada bank syariah di Kota Medan. Berdasarkan data yang di peroleh sebanyak 66 siswa memilih kategori setuju dan sangat setuju dengan pernyataan bank syariah memiliki laporan keuangan yang sehat dan 59 siswa memilih kategori setuju dan sangat setuju dengan pernyataan bank syariah tidak memiliki sengketa.

Berdasarkan Direktorat Pembinaan SMK - Kemendikbud, hingga tahun 2016 sudah ada 145 SMK yang membuka jurusan Perbankan Syariah. Dari 145 SMK tersebut, 15 SMK berstatus Negeri dan 130 berstatus Swasta. Beberapa SMK Negeri yang membuka program keahlian Perbankan Syariah diantaranya adalah SMKN 20 dan 49 Jakarta, SMKN 10 Garut, dan SMKN 1 Kudus. Sedang yang swasta diantaranya SMK TQ Al Hikmah Cirebon, SMK Muhammadiyah 3 Banjarsari, dan SMK NU Maarif Cihaurbeuti. (http://www.infosyariah.com)

Terdapat 6 mata pelajaran yang termasuk kedalam Program Kompetensi Keahlian Perbankan Syariah di SMK adalah Pengelolaan Kas, Produk Syariah, Ekonomi Islam, Akuntansi Perbankan Syariah, Komputer Akuntansi Perbankan Syariah, dan Administrasi Pajak. (http://www.infosyariah.com)

\section{METODE PELAKSANAAN}

Pengabdian ini dilaksanakan pada Bulan November 2017 di SMKN 2 Teluk Kuantan, SMKN 1 Kuantan Mudik, dan MA Pondok Pesantren Nurul Islam, di Kabutapatn Kuantan Singgingi, Provinsi Riau. Metode yang digunakan dalam kegiatan pengabdian ini adalah dengan metode:

a. Presentasi

Presentasi pengabdi lakukan dengan cara memberikan penjelasan kepada para siswa dan siswi SMK. Materi disampaikan dengan menggunakan media proyektor.

b. Diskusi 
Diskusi dilakukan dengan cara memberikan kesempatan kepada siswa dan siswa untuk bertanya mengenai materi yang telah disampaikan oleh prenseter, kemudian dijawab langsung oleh presenter.

c. Quis

Quis diberikan oleh prenster kepada para siswa dan siswi, jika salah satu siswa bisa menjawab, maka siswa tersebut diberikan hadiah dan jika salah satu siswa yang mengangkat tangan kemudian tidak bisa menjawab maka pertanyaan dilemparkan kepada siswa lain, dan jika tidak ada siswa yang bisa menjawab pertanyaan, maka pertanyaan dianggap hangus dan diberikan pertanyaan lain.

\section{HASIL DAN PEMBAHASAN}

1. Profil Sekolah

\section{a. SMKN 1 Teluk Kuantan}

SMK N 2 Teluk Kuantan awalnya adalah SMEA Teluk Kuantan berdiri dengan SK tahun 1991. Gedung yang dipakai sampai saat ini adalah gedung SPG, karena SPG dibubarkan maka dipakai oleh SMEA Teluk Kuantan saat itu.

Pertama yang menjabat Kepala Sekolah adalah Bpk. Drs. Abdullah Manan. saat itu jurusan yang ada adalah: Keuangan, Sekretaris dan Tata Niaga atau masuk dalam kelompok Bisnis dan Manajemen.

Kepala Sekolah kedua adalah Bpk. Suhardi, S.H. pada saat itu jurusan yang ada masih sama yaitu: Keuangan, Sekretasis dan Tata Niaga atau masuk dalam kelompok Bisnis dan Manajemen.

Kepala Sekolah ketiga adalah Bpk. Drs. Yuli Hermanto, pada masa beliau SMKN 2 Teluk kuantan tambah jurusan Usaha Jasa Pariwisata yang kemudian diganti menjadi Akomodasi Perhotelan. Pada saat ini SMKN 2 Teluk Kuantan mengusulkan untuk menjadi Sekolah Berstandar Nasional

Untuk kepala sekolah yang keempat adalah Bpk. Marlis, S.Pd., pada masa ini jurusan tambah Teknik Komputer dan Jaringan, sehingga SMK N 2 Teluk Kuantan mempunyai 5 jurusan, yaitu: Akuntansi, Administrasi Perkantoran, Pemasaran, Akomodasi Perhotelan dan Teknik Komputer dan Jaringan. Pada masa beliau SMK N 2 Teluk Kuantan ditetapkan menjadi RSBI atau Rintisan Sekolah Bertaraf Internasional. Setelah itu SMKN 2 Teluk Kuantan memperoleh sertifikat ISO 9001:2008 dari Sicofindo atas jerih payah sekolah sendiri. Masa tersebut SMKN 2 Teluk Kuantan juga mendapat kepercayaan untuk merakit Laptop, PC, Infocus.

Kepala sekolah yang kelima adalah Drs. Arman Yulis, MM. Pada masa ini RSBI dicabut oleh MK. Kemudian SMKN 2 Teluk Kuantan memperoleh Adiwiyata Nasional dan kemudian memperoleh Adiwiyata Mandiri. Masa ini SMKN 2 Teluk Kuantan memperoleh predikat sebagai Sekolah Berprestasi Nasional.

\section{b. SMKN 1 Kuantan Mudik}

YPKM (Yayasan Pendidikan Kuantan Mudik), yayasan inilah yang banyak mendirikan sekolah-sekolah di Kuantan Mudik, SMAN 1 Gunung Toar, SMAN 1 Hulu Kuantan, MA YPKM Kuantan Mudik, SMA Pantai dan SMK YPKM (sekarang sudah menjadi SMKN 1 Kuantan Mudik).

SMKN 1 Kuantan Mudik adalah SMK YPKM (Yayasan Pendidikan Kuantan Mudik) yang diresmikan Bupati Kabupaten Kuantan Singgi, BPK H. Sukarmis. Proses penegeriannya terletak di Desa Pulau Binjai, Kecamatan Kuantan Mudik dan menjadi satu-satunya sekolah kejuruan yang ada di Kecamatan Kuantan Mudik. Pada saat itu SMKN 1 Kuantan Mudik, jumlah siswa yang sekolah di SMK ini ada 200 
siswa dan siswi, dengan jumlah tenaga pengajar termasuk Kepsek dan TU semuanya ada 35 orang. Terdiri dari 9 guru PNS, 12 guru honorer komite dan 14 Guru Bantu (GB).

Saat ini SMKN 1 Kuantan Mudik beralamatkan di Jalan Air Panas alam, Desa Pulau Binjai, Kecamatan Kuantan Mudik, Kabupatan Kuaantan Singingi. Kepala Sekolah SMKN 1 Kuantan Mudik adalah Emzita. A.

\section{Pembahasan}

Pengabdian ini dilakukan dengan cara memberikan pengenalan ekonomi islam dan akad-akad bank syariah. Kegiatan PPM yang dilaksanakan dengan presentasi, diskusi dan kuis seputar materi.

Pelaksanan kegiatan PPM ini dilakukan oleh 2 (tiga) orang tim pengabdi dengan pokok bahasan yang disampaikan mengenai:

a. Pengenalan ekonomi islam

b. Pengenalan akad-akad bank syariah

Keterbatasan waktu pertemuan mengakibatkan tidak semua materi dapat disampaikan dengan detil dan panjang lebar.

Hasil kegiatan PPM secara garis besar mencakup beberapa komponen sebagai berikut:

a. Keberhasilan target jumlah peserta pelatihan

Target peserta penyuluhan seperti direncanakan sebelumnya adalah 20 peserta per-sekolah, Dalam pelaksanaannya, kegiatan ini diikuti oleh 53 orang peserta dengan rincian SMKN 2 Teluk Kuantan sebanyak 32 Orang, SMKN 1 Kuantan Mudik sebanyak 22 orang. Dengan demikian dapat dikatakan bahwa target peserta tercapai, bahkan ada yang melebihi kapasita kelas atau lebih dari jumlah yang diharapkan. Angka tersebut menunjukkan bahwa kegiatan pengabdian masyarakat dilihat dari jumlah peserta yang mengikuti dapat dikatakan berhasil/ sukses.

b. Ketercapaian tujuan kegiatan

Ketercapaian tujuan kegiatan pengabdian kepada masyarakat syariah secara umum sudah baik, namun keterbatasan waktu yang disediakan mengakibatkan tidak semua materi tentang pengenalan ekonomi islam dan akad-akad bank syariah tidak dapat disampaikan secara detil.

c. Ketercapaian target materi yang telah direncanakan

Ketercapaian target materi pada kegiatan pengabdian masyarkat ini cukup baik, karena materi penyuluhan telah dapat disampaikan secara keseluruhan. Materi pendampingan yang telah disampaikan adalah:

1) Pengantar ekonomi islam.

2) Akad-akad bank syariah

d. Kemampuan peserta dalam penguasaan materi

Kemampuan peserta dilihat dari penguasaan materi masih kurang dikarenakan waktu yang singkat dalam penyampaian materi dan kemampuan para peserta yang berbeda-beda. Hal ini disebabkan jumlah materi yang banyak hanya disampaikan dalam waktu 60 menit sehingga tidak cukup waktu bagi para peserta untuk memahami secara lengkap semua materi yang diberikan.

Secara keseluruhan kegiatan pengabidan ini dapat dikatakan berhasil. Keberhasilan ini selain diukur dari keempat komponen di atas, juga dapat dilihat dari kepuasan peserta setelah mengikuti kegiatan karena tim pengabdi memberikan 
kesempatan bertanya sebanyak-banyaknya dan ketika tim pengabdi memberikan pertanyaan dapat dijawab oleh siswa, apalagi bagi siswa yang bisa menjawab diberikan hadiah. Manfaat yang diperoleh peserta adalah pengetahuan dan pemahaman tentang ekonomi islam dan akad-akad bank syariah..

\section{KESIMPULAN}

Program pengenalan ekonomi islam dan akad-akad bank syariah di Teluk Kuantan, Kabupaten Kuantan Singingi dapat diselenggarakan dengan baik dan berjalan dengan lancar sesuai dengan rencana kegiatan yang telah disusun, meskipun belum semua peserta penyuluhan menguasai dengan baik materi yang disampaikan. Kegiatan ini mendapat sambutan sangat baik terbukti dengan keaktifan peserta mengikuti pengenalan ekonomi islam dan akad bank syariah dengan tidak meninggalkan tempat sebelum waktu kegiatan berakhir.

1. Keberhasilan

a. Tersedia tenaga ahli yang memadai dalam kegiatan ini, karena yang menyampaikan adalah dosen ekonomi syairah yang dalam kesehariannya mengajar mata kuliah tersebut.

b. Antusiasme siswa dan siswi SMK sederajat yang tinggi terhadap kegiatan ini, terbukti dengan banyaknya pertanyaan yang disampaikan kepada pemateri dan quis yang diberikan dapat dijawab dengan baik oleh para siswa tersebut..

c. Dukungan Kepala Sekolah SMKN 2 Teluk Kuantan dan SMKN 1 Kuantan mudik terhadap kegiatan ini menambah semangat pengabdi dalam kegiatan pengabdian ini, sehingga mempermudah dan membantu tim pengabdi dalam mengelolaan waktu dan tempat pelaksanaan kegiatan.

d. Ketersediaan dana pendukung dari Universitas melalui Lembaga Penelitian dan Pengabdian Kepada Masyarakat guna penyelenggaraan kegiatan ini.

2. Hambatan

a. Siswa dan siswi SMK Kabupatan Kuantan Singingi se-Derajat yang merupakan peserta penyuluhan masih banyak yang belum memiliki pengetahuan tentang ekonomi islam dan akad bank syairah, sehingga butuh waktu dalam menjelaskannya.

b. Keterbatasan waktu untuk pelaksanaan pengenalan ekonomi islam dan akad bank syariah sehingga beberapa materi tidak dapat disampaikan secara lebih teperinci dan gamblang.

c. Daya tangkap para siswa yang bervariasi, ada yang cepat menangkap materi dan ada juga yang lambat dalam menerima materi, sehingga waktu yang digunakan kurang maksimal, sehingga waktu yang ada tidak cukup untuk menjelaskan semuanya.

\section{UCAPAN TERIMAKASIH}

Pengabdian ini merupakan bagian dari kegiatan dosen STEI Iqra Annisa Pekanbaru untuk mengetahui tingkat pemahaman siswa dan siswi SMk di Teluk Teluk Kuantan, Kabupaten Kuantan Singingi. Pengabdi ucapakan terima kasih yang tak terhingga kepada Kepala Sekolah SMKN 2 Teluk Kuantan dan SMKN 1 Kuantan Mudik yang telah memberikan kesempatan untuk mengadakan kegiatan pengadian di lembaga yang Bapak Pimpin. Semoga silaturahim ini tetap terjalin untuk pengabdian yang selanjutnya. 
Pengabdi juga berterima kasih kepada Lembaga Penelitian dan Pengabdian Kepada Masyarakat STEI Iqra Annisa yang memberikan kesempatan dan support dana untuk kegiatan pengabdian masyarakat ini.

\section{DAFTAR PUSTAKA}

[5]. Ismail, Perbankan Syariah, Prenada Media, Jakarta. 2011.

[6]. Muhammad Abdallah Dan Irsyad Lubis, Analisis Minat Menabung Pada Bank Syariah Di Kalangan Siswa Sma Di Kota Medan (Studi Kasus: Siswa Madrasah Aliyah Negeri) Dalam e-jurnal http://jurnal.usu.ac.id index.php/edk /article/viewFile/11765/5124 diakses tanggal 11 Maret 2017.

[7]. Mustahdi dan Mustakim. Pendidikan Agama Islam dan Budi Pekerti, Jakarta: Kementerian Pendidikan dan Kebudayaan. 2014.

[8]. Soemitra, Andri. Bank dan Lembaga Keuangan Syariah, Cetakan Kedua,, Jakarta: Prenada Media, 2009.

[9]. Dokumentasi SMKN 2 Teluk Kuantan

[10]. Dokumentasi SMKN1 Kuantan Mudik

[11]. smkn2telukkuantan.sch.id 